\title{
Investigating peer and teaching assistant interactions of physics students working on computational coding
}

\author{
Zack Rowatt, Rebecca Rosenblatt, and Raymond Zich \\ Department of Physics, Illinois State University, Normal, IL, 61790
}

\begin{abstract}
Video and audio data were recorded from five computational coding based labs completed as part of an introductory modern physics course. Three small cube cameras, a larger camera with microphone that could see the whole room, and four live scribe pens recording additional audio were used to document the activities. Several themes emerged from the videos. A major theme was how lab time was spent (on task vs. off task, about physics vs. about computation, on general principles vs. solving a specific problem, working alone vs. together) and what caused students to transition between these different activities. Other major themes were the mood and engagement of students while working in these different areas and where/how patterns of communication were different from those seen for non-computational problem solving activities. We will present these findings and discuss their implications for peer communication and learning in introductory computational physics courses.
\end{abstract}

\section{THEORETICAL FRAMING AND METHODOLOGY}

Student engagement plays a critical factor in student learning [1]. Research shows that active collaborative environments yield beneficial results for student learning during physics problem solving [2-4]. So, it might be assumed that a similar environment would be beneficial for students solving physics problems with computers. However, it is also known that the arrangement of a classroom in regard to the physical layout has far reaching effects on classroom engagement and student to instructor rapport [5]. Only minimal research has been done on computational physics labs and the effects computers have on peer interactions $[6,7]$. Here we used one of the theoretical models suggested by Otero and Harlowe [8] - and used by several other qualitative researchers $[9,10]$ to inductively analyze classroom video data and report on the effects that computational problem solving has on student engagement.

The model used takes video data and builds a working theory about that data from watching some of the video and then progressively refines this theory via videos watched later [8]. In watching and taking field notes of the initial video from the Fall 2016 semester [8, 11], it was observed that there were highly diverse Teaching Assistant (TA) to student interactions and quite a lot of time spent off task - more than $33 \%$ of the time off task for some students. This motivated the research analysis that was made on the set of five videos for the Spring 2017 semester and which is presented in this article. For spring semester videos, a rubric - similar to the one Sawada et al. used to look at teaching - was used to document the number and length of peer interactions both student to TA and student to student interactions and the amount of time students spent on and off task [12]. The following is a presentation of the behaviors observed in this study of peer interactions and student use of class time; our question is what instructional and environmental factors lead to on task and off task behaviors.

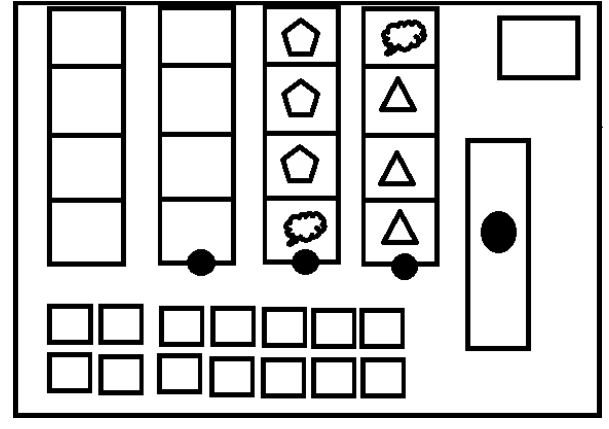

FIG. 1. Classroom layout for spring semester 2017. Adjacent and individual squares represent student work spaces. Like shapes denote frequent student collaborations. Black circles represent camera placement. The front of the room is on the right hand side.

\section{A. Classroom Setting and Population Investigated}

The environment filmed and observed was a medium size computer lab used for computational physics courses. The arrangement of the classroom was four rows of desks, each containing four individual Macintosh computer stations, facing the front of the classroom where a smart board and white board allow for whole class presentations (see Figure 1). The students were third semester physics majors taking the introductory modern physics course and completing the computational lab component of the course, which met in three hour blocks semiweekly. The Spring 2017 student sample was 8 students, 6 males and 2 females. Both semesters relevant to us had the same undergraduate teaching assistant (TA). Students usually filled the same seats of the lab from week to week but those in the second and third row would alternate due to issues with some of the Macs.

The recording equipment consisted of three Polaroid cube cameras, which were aimed down the rows, a higher quality Canon Vixia that observed the class as a whole, and four Live Scribe pens that were placed halfway along each row and were used to record extra audio as the cube cameras' audio quality is limited (See Figure 1). 


\section{B. The Computational Tasks \& Student Difficulties}

The recorded computational assignments built off of introductory labs from earlier in the course and required students to use the Mathematica to complete these more complicated tasks. In these 5 labs, numbered in order by date, students were expected to: 1 . Practice computational skills with distributions and uncertainty. 2. Solve differential equations with the Euler Method and use these to find piston motion. 3. Apply the Monte-Carlo technique to photons in a double slit experiment with wave interference. 4. Solve the radial aspect of Schrodinger's equation for the Hydrogen atom using the Finite-Difference Method. 5. Code the Hamiltonian and use creation and annihilation operators to study the Higgs boson.

Procedure - converting the physics into programming statements - and syntax were the aspects of the computational labs which proved most difficult for students. Within lab assignments, procedure questions were usually able to be answered quickly by peers and the TA; syntax issues were less easily remediated and usually required the TA and a longer discussion. These issues of procedure and syntax appeared on their own throughout the labs, but when they occurred in conjunction, the greatest amount of student frustration was observed.

As students worked, their understanding of the labs and engagement in the tasks, which were closely related, was reflected in the interactions they had with the teaching assistant and each other as well as how they spent their time both ontask and off-task. The teaching assistant worked to accommodate and remediate student difficulties by rephrasing certain directions, questioning students, examining their code, and reinforcing it all with encouragement. Here we will describe the diverse communication and collaboration behaviors observed as students worked on these computational tasks and the researchers' inferences as to the causes of these communication variations.

\section{CLASSROOM INTERACTIONS}

Classroom interactions within the computational labs varied due to a wide range of factors. Those discussed in this section focus on interactions that are on task and pertinent to the lab, i.e. not social conversation. Some of the factors affecting classroom cohesion and efficacy were apparent/perceived difficulty of assigned work, preexisting student content knowledge, and the number of students present. Interactions within the classroom were categorized by observation protocols and analyzed by their length (long vs. short) and whether they were student to teaching assistant interactions or student to student collaborations. Student to student collaborations observed were often the result of the teaching assistant being preoccupied assisting others. Table I displays the average number of interactions students had with the TA, average length of interactions, and percentage of the total number considered short (less than three minutes).
TABLE I. Student to TA interactions categorized by number, average length, and percent of short interactions. The lab number indicates the topic - see section I-B.

\begin{tabular}{|c|c|c|c|c|}
\hline Lab & Date & Avg. \# Interactions & Avg. Time & $\%$ Short Int. \\
\hline 1 & March 2nd & 2.5 & $3: 05$ & 65 \\
\hline 2 & March 9th & 2.6 & $1: 52$ & 78 \\
\hline 3 & April 6th & 3.3 & $2: 05$ & 78 \\
\hline 4 & April 13th & 6.67 & $2: 12$ & 70 \\
\hline 5 & May 4th & 1.3 & $5: 19$ & 25 \\
\hline
\end{tabular}

\section{A. Long Student-TA Interactions}

Long interactions were classified as those lasting more than three minutes. These long interactions contrasted highly with their shorter counterparts and came in two forms depending on the difficulty of the lab. In less difficult labs that required relatively low amounts of TA assistance, long TA to student interactions took the form of general questions that were usually able to be answered from the front of the room and the TA's comments were helpful to many students. During these periods, the classroom environment assumed a more traditional lecture setting with students usually being engaged and concentrating on the TA's explanations.

In the labs deemed most difficult because of observed student hesitancy and comments, long TA to student interactions took the form of individual student interactions. In this case, long interactions were typical of only a fraction of the students and these interactions tended to monopolize the teaching assistant's time. These were not procedure issues; they were syntax or code errors that required the TA to hunt through the student's code. Interestingly, when the TA came to assist the student, the student usually stopped engaging in the problem themselves. In nearly every case where the TA sat at a student's seat and entered or fixed the code, that student became completely disengaged. Students would use the time the TA was looking at their code to check their cell phones, leave the room briefly, or talk with other students as the TA worked.

\section{B. Short Student-TA Interactions}

On the opposite end of the spectrum, interactions among the teaching assistant and students that were less than three minutes in length were often the result of quick procedure questions and clarifications of values and variables. These interactions were common in lab assignments where students were more comfortable with the concepts and required code and therefore needed less one on one time with the teaching assistant. (Lab 2 dealing with the Euler method was a good example of this.) The TA would often repeat discussions had with two or three students as groups of students elsewhere in the room would encounter the same issues. 
These shorter interactions were in sharp contrast with the dynamic seen in the long interactions as students remained engaged for the duration of their interaction with the TA. These interactions did not allow the students to disengage as they were required to be focused to understand the conceptual problems in their work. Labs which comprised mostly of short TA interactions, allowed the TA to talk to and ask questions of small groups of students and this appeared to be more beneficial for student learning than the long individual assistance.

The relative breakdown for the number of short interactions to long for the labs shows that short interactions typically accounted for about 75 percent of TA interactions (see Table I). The other 25 percent generally revolved around locating the sources of error in codes and the TA cleaning up code to make it easier for both parties to navigate.

\section{Student-Student Interactions}

The third type of interactions within the classroom involved those between students. Students typically interacted with the closest students along a row. Some students did move about the room and confer with others between rows, but these long range interactions were largely the result of specific students knowing how to do something and the TA being currently occupied helping other students.

Pairs and groups of three that worked together stayed the same, for the most part, over the course of the five computational labs and were a result of the set up of the room and nearness of certain peers as seen in Figure 1. The rows appeared to stick together as a matter of convenience and who sat in which row was a relatively important factor concerning who worked together that day and the ways in which they collaborated.

While students were welcome to work together, there were still students who chose to work independently. Students who worked independently often sat by themselves and consequently had to move when they did confer with other students. This is not to say that these students were aloof or reluctant to work with others; the circumstances and environment of the day's lab seemed to affect where students sat on that day and this in turn seemed to affect how much they collaborated.

\section{OFF-TASK STUDENT BEHAVIOR}

Off task behavior occurred when students spent their time visibly engaged in matters not related to the laboratory activities. The greatest sources of student distraction included cell phone usage and social conversation among peers. Other types of off task behavior included leaving the room, arriving late, or leaving early. Data concerning student engagement and relative times spent off task are shown in Table II.
TABLE II. Average number of instances of student off task behavior, relative time lengths, and average number of on task peer-to-peer interactions.

\begin{tabular}{|c|c|c|c|c|}
\hline Lab & Date & $\begin{array}{c}\text { Avg. \# Interact. } \\
\text { (Off Task) }\end{array}$ & $\begin{array}{c}\text { Avg. Time } \\
\text { (Off Task) }\end{array}$ & $\begin{array}{c}\text { Avg. \# Peer Int. } \\
\text { (On Task ) }\end{array}$ \\
\hline 1 & March 2nd & 3.25 & $2: 58$ & 6.63 \\
\hline 2 & March 9th & 7 & $6: 04$ & 9.86 \\
\hline 3 & April 6th & 4.29 & $5: 26$ & 7.43 \\
\hline 4 & April 13th & 5.83 & $5: 34$ & 11 \\
\hline 5 & May 4th & 5.33 & $20: 34$ & 3.67 \\
\hline
\end{tabular}

\section{A. Cell Phone Usage}

Cell phone usage was a major factor of student disengagement within the computational labs. While most students used their phones in short spurts to either send messages or quickly look at something, there were students who spent large amounts of lab time on their devices. It was usually the same two or three students each lab who were likely to be off task and on their phone. Similar to the student-student interactions discussed above, students would often use their phones if they needed to wait for aid from the teaching assistant. In the labs that required longer TA involvement, this was common as these labs were the more difficult and usually saw multiple students struggling.

\section{B. Social Conversation}

Similar to usage of phones, conversation occurred when students either were stalled and not making progress on the lab, simply did not care to work on the lab, or were making progress but experiencing difficulty at that time. Conversations between students that were prolonged, even if the conversation initially was about the task, often lead to students being off task. This means that, counter intuitively, students were off task more often in labs that had higher instances of student to student on task interactions. As before with cell phone usage, it was a select few students who were more apt to be off task through conversation. However, unlike with cell phone usage, conversations often resulted in an entire small group becoming distracted. Also, social conversation would spill between rows in ways that discussion pertinent to the lab did not.

For the most part, off task conversations concerned personal experiences or plans, other physics course work, absent students, and the cameras in the room. The cameras were a recurring source of short conversations as students initially questioned their presence and later discussed the recording of unsavory language, but most of the time students did not seem self-conscious or even aware of being filmed; this is consistent with observations of others on how students treat cameras [13]. It should be noted that while off task conversa- 
tions did not assist in students learning of physics directly, it is not clear that they negatively impacted student learning.

\section{IMPLICATIONS FOR INSTRUCTION}

In these five computational labs, the following was observed. The majority of students' time was spent working separately but collaboratively and on problem specific issues. Students had very few issues with the physics in the labs but did have computational issues. Students had the most computational problems with procedure and syntax. Both required longer TA assistance, but procedure questions could be handled with whole class discussions or small group interventions that preserved student engagement while syntax required one on one help that promoted heavy student disengagement.

Additionally, this video analysis showed that students were off task the most when they needed TA assistance and none was available. Students were off task when the difficulty of the assignment did not properly match student preparation either because the instructions were not clear or students had insufficient preexisting knowledge of the relevant programming concepts or failed to prepare adequately. Simpl put, students were off task when the assignment created many student specific syntax errors that necessitated large amounts of TA time to find and address.

Other findings showed that some students were more likely than others to be off task independent of the lab activity, students naturally conferred with those around them, and short interactions and TA explanations to a small group were the most helpful for student learning and for keeping students on task. It is important to reiterate that although labs that were characterized by high averages of students being off task, these same labs featured the highest numbers of on task peer to peer interactions. This in addition to the fact that they are the same three sections with the highest number of short interactions lead to the following conclusions. In conjunction with this, the same three labs had the highest percentage of short interactions and thus more equally distributed TA time.

It is clear that the TA should never sit down in front of someone else's work because that student simply stops working. Certain students may benefit from mentoring to help keep them engaged and on task and to limit the negative impact they have on other students when they initiate off task conversations. Also, it seems that computational instruction, like problem solving, should be designed to have the students work together and reach a solution collaboratively as opposed to requiring individual work as is the current format of this course. By creating group assignments, it may be possible to renegotiate the classroom environment so that students look to each other for assistance over the TA as they clearly do currently. Also, collaborative groups would allow the TA more time to interact with the groups as the group takes ownership of hunting for syntax mistakes which took up much of the TA's time. These findings apply to more than just computational labs as the data suggests students should use others as sources of solutions on their own or through TA facilitation in order to avoid rampant individual disengagement when difficulties do arise.

Future research suggested by this project is to investigate the effect of redesigning the curriculum for group projects, the computational difficulties encountered and better ways to address these difficulties in the classroom, and the effects of training for the teaching assistant in how to encourage positive student self-efficacy and engagement. There is the additional potentiality of looking at the characterization of teaching assistant interactions with students in non-computational courses for more informative data concerning individual and group interactions from a more general instruction perspective.

\section{ACKNOWLEDGMENTS}

Thank you to Rebecca Lindell for the advice and support as well as to the Illinois State University Department of Physics and Dr. Christensen and his students.
[1] J. Dunleavy, and P. Milton, Educating Canada, 48(5), 4-8, (2008).

[2] P. Heller, R. Keith, S. Anderson, Am. J. Phys. 60, 627 (1992).

[3] C. Crouch and E. Mazur, Am. J. Phys. 69, 970-977 (2001).

[4] P. Heller, M. Hollabaugh, Am. J. Phys., 60, 637 (1992).

[5] A. V. Knaub, K. T. Foote, C. Henderson, M. Dancy, and R. J. Beichner, International Journal of STEM Education, 3(8), (2016).

[6] G. J. Kelly and T. Crawford, Journal of Research in Science Teaching, 33(7), 693-707, (2006).

[7] M. J. Obsniuk, P. W. Irving and M. D. Caballero, PERC Proceedings, (2015).

[8] V. K. Otero and D. B. Harlowe. In Getting Started in PER, edited by C. Henderson and K. A. Harper, Reviews in PER Vol. 2, (2009).

[9] D. R. Thomas, Am. J. Eval. 27, 237 (2006).

[10] R. A. Engle, F. R. Conant, J. Greeno, R. Goldman, R. Pea, B. Barron \& S. J. Derry (Eds.), Mahwah, NJ: Lawrence Erlbaum Associates.

[11] F. Erickson, in Handbook of Complementary Methods in Education Research, edited by J. Green, G. Camilli and P. Elmore (Lawrence Earlbaum, Mahwah, NJ, 2006).

[12] D. Sawada, M. Pilburn, E. Judson, et al., Sch. Sci. \& Math 102, 245 (2002).

[13] B. Jordan and A. Henderson, J. Learn. Sci. 4, 39 (1995). 